\title{
Educational Review
}

\section{Dynamic assessment: a case of unfulfilled potential?}

\author{
Julian G. Elliott, Wilma C. M. Resing \& Jens F. Beckmann
}

To cite this article: Julian G. Elliott, Wilma C. M. Resing \& Jens F. Beckmann (2018)

Dynamic assessment: a case of unfulfilled potential?, Educational Review, 70:1, 7-17, DOI:

10.1080/00131911.2018.1396806

To link to this article: https://doi.org/10.1080/00131911.2018.1396806

$$
\text { 曲 Published online: } 09 \text { Jan } 2018 .
$$

Submit your article to this journal

LIII Article views: 531

View Crossmark data \lceil 


\title{
Dynamic assessment: a case of unfulfilled potential?
}

\author{
Julian G. Elliott ${ }^{a}$ DD, Wilma C. M. Resing ${ }^{b}$ (D) and Jens F. Beckmann ${ }^{c}$ \\ ${ }^{a}$ Collingwood College/School of Education, Durham University, Durham, UK; ${ }^{b}$ Department of Developmental \\ and Educational Psychology, Faculty of Social Sciences, Leiden University, Wassenaarseweg, The Netherlands; \\ 'School of Education, Durham University, Durham, UK
}

\begin{abstract}
This paper updates a review of dynamic assessment in education by the first author, published in this journal in 2003. It notes that the original review failed to examine the important conceptual distinction between dynamic testing (DT) and dynamic assessment (DA). While both approaches seek to link assessment and intervention, the former is of particular interest for academic researchers in psychology, whose focus is upon the study of reasoning and problem-solving. In contrast, those working in the area of dynamic assessment, often having a practitioner orientation, tend to be particularly concerned to explore the ways by which assessment data can inform educational practice. It is argued that while some authors have considered the potential value of DA in assisting classification, or in predicting future performance, the primary contribution of this approach would seem to be in guiding intervention. Underpinning this is the view that DA can shed light on the operation of underlying cognitive processes that are impairing learning. However, recent research has demonstrated that the belief that deficient cognitive/executive functions could be identified and ameliorated, and subsequently result in academic progress, has not been supported. Where gains in such processes/functions have sometimes been found in laboratory training studies, these have tended not to transfer meaningfully to classroom contexts. The review concludes by pointing out that DA continues to be supported primarily on the basis of case studies and notes that the 2003 call for research that systematically examines the relationship between assessment and intervention has yet to be realised.
\end{abstract}

\section{KEYWORDS}

Dynamic assessment and testing; learning potential; cognitive education; brain training

Imagine a form of educational assessment in which the assessor and the child collaborate to help the latter perform more capably on the test. At the outset, the assessor gauges the child's unassisted ability and, in the light of the rich information that is provided, subsequently provides the support necessary to effect improved performance. The amount of support is carefully calibrated to ensure that it is neither too little nor too great. Key to this process is the need to gain a sound understanding of the cognitive abilities of the child, their responses to challenge, and the ways that they utilise or disregard the assessor's inputs. 
Thus, assessment focuses both upon academic performance and the cognitive processes that are considered to underpin this. Surely, such an approach closely mirrors the nature of the multiple interactions that constantly take place between teacher and student in classrooms all over the world? Wouldn't this form of assessment provide teachers with far greater insight into the child's potential, while also pointing to the best ways to help those struggling to maximise their learning?

Compare this approach with those forms of psychological assessment that are most commonly utilised in education settings, for example, intelligence testing. Here the administration of the test is usually closely scripted and, beyond brief familiarisation of material, and recognition of the need for the assessor to establish rapport, any assistance in the problem-solving process would typically be seen as introducing error into the measurement. Scores derived from such tests are considered to primarily indicate the current ability, rightly or wrongly, of the child. This assumes that the child fully understands what is being asked of them, and is in a position to perform to the best of their ability. The difficulties of those children who shrink from the challenges of initial failure, unfamiliar content or the experience of a daunting interpersonal dynamic are not easily addressed by such an approach. The gap between what the child can achieve unassisted and that which s/he can accomplish with help (the zone of proximal development) cannot be identified.

Given the distinction between these two approaches, it is hardly surprising that many educationalists and psychologists are instinctively drawn to the merits of dynamic assessment, an umbrella term that refers to a wide range of approaches typified by the provision of instruction and feedback as part of the testing process. Fifteen years ago, the first author (Elliott 2003) outlined the history and nature of dynamic assessment, discussed some of the educational functions that these could serve, specified a number of challenges, and offered recommendations for the future. The current paper serves as a reflection upon the progress that has been made since this time.

In this short account, we do not propose to provide a detailed account of the theoretical origins, or a description of the different approaches, of dynamic assessment. In our opinion, the account provided in the 2003 paper continues to perform this function adequately. Rather, we will focus upon the progress made in relation to the functions of dynamic assessment and consider whether it has fulfilled its potential. However, prior to undertaking such analysis, it is necessary to highlight that the original paper did not sufficiently critique the tendency to treat synonymously a number of key concepts such as dynamic assessment, dynamic testing, learning ability (Guthke 1982), cognitive modifiability (Tzuriel 2013), trainability (Kern 1930), intellectual change potential (Beckmann 2001) and learning potential (Hessels 2009). As Beckmann (2014) points out, if these terms do not all mean exactly the same thing (and opinions will differ in this respect), the establishment of the construct validity of each would need to focus on rather different criteria. As a result, it is possible that one might find oneself in a situation where, for example, dynamic tests of learning ability might prove to be more successful than dynamic tests of cognitive modifiability. Clearly, there is much conceptual work to be undertaken here.

The conceptual distinction between dynamic assessment and dynamic testing is important to highlight. This was not adequately addressed in the 2003 paper and the important differences of emphasis are often implicit, rather than explicit, in both the academic and professional literature. While both dynamic testing and dynamic assessment seek to link assessment and intervention, the focus of dynamic testing is principally with the test itself; 
in contrast, the primary focus of dynamic assessment is the intervention that follows. Dynamic testing is arguably of greater interest to academic and research psychologists. It represents a methodological approach to the psychometric assessment of intellectual functioning that uses systematic variations of task characteristics and /or situational characteristics in the presentation of test items with the intention to evoke intraindividual variability in test performance. Interindividual differences in intraindividual variation are seen as more adequately reflecting the dynamics in the organisation of human behaviour, including learning and cognitive flexibility (Beckmann 2014; Guthke and Beckmann 2000; Guthke, Beckmann, and Wiedl 2003; Guthke and Wiedl 1996). In multiple studies, spanning many years, Resing and her colleagues (e.g. Resing and Elliott 2011; Resing et al. 2012, 2016; Resing, Bakker, et al. 2017; Resing, Touw, et al. 2017) have utilised dynamic testing to improve our understanding of differences in the approaches and strategies employed by children in a variety of problem-solving situations. It is important to note, however, that while such work has proven highly informative for academic psychologists and researchers, it has yet to provide significant insights that can inform individualised instruction for specific children.

In general, intervention in dynamic testing is a means to help the psychometric assessment process and to help us understand differences and commonalities in learning and problem-solving. In contrast, the focus of dynamic assessment is principally upon effecting intervention. To achieve a meaningful intervention for a given individual, dynamic assessment typically embraces a wide range of cognitive, affective and conative elements. Unsurprisingly, this latter approach generally has greater appeal to educationalists and clinicians. An illustration of this important distinction was the experience of the first author who, many years ago, travelled overseas to learn from one of the field's leading researchers. After demonstrating a sophisticated range of dynamic tests, the professor was asked how these could be used to support intervention work with children. His response was that as a research psychologist, this was no concern of his. In his opinion, any application of his measures to practitioner activity was the responsibility of educationalists.

In the rest of this paper, the primary focus will be upon the development of dynamic assessment over the past 15 years. While work in dynamic testing should not be divorced from this consideration, the key consideration will be upon the extent to which dynamic approaches have fulfilled their promise in relation to educational practice.

Elliott (2003) posed the important question as to what should be the purpose of dynamic assessment. Was it to be primarily a means of:

- making more accurate educational classifications (e.g. gifted or intellectually disabled) that might inform programming and resourcing,

- providing superior predictions of future performance (that might assist in identifying those who would make maximum gains given further assistance) or

- providing detailed information about the individual child in ways that can help educationalists provide an individually tailored intervention matched closely to his or her particular needs

Elliot (2003) provided a detailed critique of the use of dynamic assessment for the purposes of classification and labelling. It is our opinion that the points that were made are equally relevant today and it is unnecessary to repeat these in the present paper.

Given the emphasis so often found in educational psychology upon prediction, it is not surprising that many papers in the research literature focus upon dynamic assessment's 
potential for superior prediction (Caffrey, Fuchs, and Fuchs 2008). Such a focus has been strengthened by the growth of the response to intervention movement (RTI) in the United States and elsewhere. This approach seeks to identify those who are struggling, or are at risk of future failure, in key academic and behavioural domains. Rather than operating a "wait to fail" model in which clinical assessment occurs months or, as is often the case, several years later, RTI seeks to provide supportive action as soon as difficulties become apparent. The extent of the support offered at various tiers, or levels, of provision is a function of the level of progress that the child is making, rather than on the basis of a given diagnostic label.

A key challenge for RTI models has been the difficulty in determining how one can make the best-informed decisions about the amount and forms of help required for each child. It has been argued that dynamic assessment may be a relatively rapid way of making sound judgements about which tier/level is appropriate for a given child (Caffrey, Fuchs, and Fuchs 2008; Cho et al. 2014). Spurred by the need to inform educational practice more effectively, there has been a significant shift in dynamic test content from problem-solving measures that resemble items typically found on IQ tests (e.g. Stevenson, Heiser, and Resing 2016) to those in academic domains and the related curriculum itself (Cho et al. 2014; Compton et al. 2010) in particular, literacy (Aravena et al. 2016; Gellert and Elbro 2017) and mathematics (Peltenburg, van den Heuvel-Panhuizen, and Doig 2009; Seethaler et al. 2016). A further area that has received much attention is language (King, Binger, and Kent-Walsh 2015), including the needs of those whose first language is not that used in school and who, therefore, may score poorly on commonly used standardised test measures (e.g. Petersen and Gillam 2015; Seethaler et al. 2016). It is likely that the predictive quality of these curricular measures will be highly domain specific (Cho and Compton 2015; Grigorenko 2009).

A further development in recent times has been an increasing use of computerised forms of dynamic assessment (McNeil 2016; Poehner, Zhang, and Lu 2015; Resing, Tunteler, and Elliott 2015; Zhang et al. 2017), even involving the use of 3D immersive environments (Passig, Tzuriel, and Eshel-Kedmi 2016). One of the major contributions of computerised approaches is that these can utilise tangible materials that can lead to the capture of a mass of data (e.g. response latencies) that are not easily obtainable, or recorded, as part of the complex interpersonal dynamics of human-human testing (Resing and Elliott 2011; Resing, Touw, et al. 2017; Veerbeek et al. 2017). It will be interesting to see whether the development of what is likely to be an increasingly rich area of research will succeed in resolving the fundamental questions raised in the 2003 review, and which are further addressed below. Alternatively, maybe increased use of computerisation will ultimately lead to alternative understandings concerning the value of dynamic approaches, for example, removing the need for one-toone clinical work (Dumas and McNeish 2017; McNeish and Dumas 2017).

Attempts to validate dynamic assessment have largely sought to identify how students will progress in the future. However, in relation to prediction, the field has yet to resolve a fundamental theoretical and practical issue that was raised in Elliott (2003). Let's take a concrete example to illustrate this. Olivia is struggling in school. Her standardised test scores are low, as would be expected. Dynamic assessment indicates that she has much untapped potential. However, unless the child's environment is transformed in some meaningful fashion, her potential is unlikely to be revealed and the prediction will fail; thus, the predictive validity of dynamic assessment must be seen to be a function of the educational environment in which it operates. Of course, changing an educational environment is no easy task. It is far easier to speculate on a child's future potential than use the information from the 
assessment to inform subsequent practice in a meaningful fashion. As Haywood $(1993,5-6)$ so adroitly noted:

... Prediction never was a particularly defensible objective. I could never understand what makes psychologists want to be fortune tellers! There should be scant satisfaction in knowing that our tests have accurately predicted that a particular child will fail in school. There are many sources of such predictor information. What we need are instruments and approaches that can tell us how to defeat those very predictions! (emphasis as in original.)

To some extent, RTI approaches offer the possibility of using assessment to make a difference to educational practice. Underpinning the approach is the expectation that the particular needs of students will be identified, and appropriate forms of intervention will be provided. However, RTI is essentially a way of structuring assessment and intervention; the educational practices that are used within this approach must be determined separately. So can dynamic assessment help with this? We now turn to consider whether dynamic assessment can provide educationalists with insights about any given student that can inform the nature of subsequent individualised intervention.

Elliott (2003) identified the approach of Feuerstein and colleagues $(1979,1980)$ as one that closely linked dynamic assessment with subsequent intervention. While the conceptual and theoretical breadth and depth of Feuerstein's work is impressive, his assessment tool, the Learning Potential Assessment Device, later retermed the Learning Propensity Assessment Device, (LPAD) has largely failed to gain a significant foothold in education circles. It was noted in Elliott (2003) that challenges stemmed from the lack of accessibility of its language to teachers, and a lack of conceptual clarity (Büchel and Scharnhorst 1993; Guthke and Beckmann 2000; Sternberg and Grigorenko 2002). Since this time, a further powerful criticism is that, over the past three decades, Feuerstein's theory and concepts, and the assessment tool derived from these have not advanced significantly in parallel with progress in psychological science. Despite these criticisms, and the relatively scarce use of his assessment tool, Feuerstein's seminal contribution to our understandings about children's ability, potential and how we might assess these, has been highly influential to the work and orientation of many psychologists and educationalists.

The notion that dynamic assessment could identify what Feuerstein and colleagues called "deficient cognitive processes" which could then be remediated, and ultimately result in improved academic performance, has proven attractive to many. It received extra traction from the popularity of the "thinking skills" movement that was becoming increasingly influential in schools (Fisher 2005; McGuinness 1999). This interest has been boosted more recently by the rapidly growing interest in executive functioning, a term wholly absent from the Elliott (2003) paper. Executive functioning is something of an umbrella term that is used to describe a variety of cognitive processes that are used for the completion of a task, rather than for situations which require an automatic, instinctive response. While arriving at an agreed definition of executive functioning is problematic (Cirino and Willcutt 2017) and opinions vary on which processes should be included, core executive functions would appear to involve (a) the capacity to inhibit one's actions appropriately (to exercise impulse-control and to control one's selective attention), (b) working memory and (c) cognitive flexibility (Beckmann 2014; Diamond 2012, 2013).

If a child is experiencing significant attentional or self-regulatory difficulties it is unlikely that their learning will be optimal. It is unsurprising, therefore, that a relationship has been found between executive functioning and performance in literacy (Borella, Carretti, and 
Pelgrina 2010; Bull and Scerif 2001), mathematics (Duncan et al. 2007; Sasser, Bierman, and Heinrichs 2015) and science (Nayfield, Fuccillo, and Greenfield 2013). However, whether such relationships are causal is rather less clear (Jacob and Parkinson 2015).

As noted above, it has been argued that a potential strength of dynamic assessment is that having identified cognitive (and executive) functioning difficulties, cognitive intervention programmes could be put into place to remediate these. Here, however, a mixed picture has emerged. While some (Diamond 2012, 2013; Wass, 2015) contend that cognitive training programmes are powerful means to improve executive functioning, others are less readily persuaded that such interventions will follow through to academic improvement (Cirino et al. 2017; Elliott and Resing 2015; Redick et al. 2015). While this debate has largely taken place outside of the dynamic assessment literature, it has crucial importance for those who believe that it is important to assess cognitive processes to better inform educational intervention. Opinions on this issue continue to be strongly divided. In one camp are those (often psychometricians) who believe that individualised interventions in academic areas require an understanding of underlying cognitive functioning (Decker, Hale, and Flanagan 2013). Thus, in relation to reading difficulties, Reynolds and Shaywitz (2009, 46-47) argue:

One of the major purposes of a comprehensive assessment is to derive hypotheses emerging from a student's cognitive profile that would allow the derivation of different and more effective instruction. By eliminating an evaluation of cognitive abilities and psychological processes, we revert to a one-size-fits-all mentality where it is naively assumed that all children fail for the same reason ... At the current stage of scientific knowledge, it is only through a comprehensive evaluation of a student's cognitive and psychological abilities that we can gain insights into the underlying proximal and varied root causes of reading difficulties and then provide specific interventions that are targeted to each student's individual needs.

Members of the other camp (e.g. Fletcher and Vaughn 2009; Fletcher et al. 2007, 2013; Gresham 2009) dispute the value of assessing underlying cognitive profiles of strengths and weaknesses as, other than in case study reports, there is very little evidence that such assessments can lead to differentiated forms of intervention that are effective. Fletcher, a powerful critic of cognitive profiling approaches asserts:

Despite claims to the contrary (Hale et al. 2008) there is little evidence of Aptitude x Treatment interactions for cognitive/neuropsychological skills at the level of treatment or aptitude (Reschly and Tilley 1999, 28-29). The strongest evidence of Aptitude x Treatment interactions is when strengths and weaknesses in academic skills are used to provide differential instruction. (Fletcher 2009, 506)

The evidence in support of the use of cognitive training programmes for improving educational attainment is not encouraging. Kearns and Fuchs (2013) undertook a review of 50 studies where cognitively focused instruction was employed either in isolation, or alongside academic interventions, to help children who were struggling with their learning. Few of these demonstrated that cognitive interventions were effective, and this number decreased when academic instruction was not an element in the intervention.

There does seem to be supportive evidence that specific cognitive/executive processes can be improved (at least, in the short term) by training programmes in laboratory settings (Dunning, Holmes, and Gathercole 2013; Holmes, Gathercole, and Dunning 2009). One would surely anticipate that daily practice of a particular skill using very constrained laboratory tasks would ultimately improve performance in that task, in part because of the constant feedback about a narrow task, and a likely focusing of attention upon what is needed to succeed. However, it is unclear whether gains observed in the laboratory merely reflect 
practice effects and/or the development of a more effective test strategy (Estrada et al. 2015; Hayes, Petrov, and Sederberg 2015) that is unique to that setting.

The key problem in cognitive education or "brain-training" programmes is that any gains found in laboratory studies do not appear to transfer to real-world settings, such as classrooms (Kirk et al. 2015; Redick 2015; Simons et al. 2016). This problem is particularly common in interventions for working memory difficulties for children struggling with literacy development (Banales, Kohnen, and McArthur 2015; Melby-Lervåg and Hulme 2013; Redick et al. 2015). However, even addressing underlying cognitive problems in real-world settings may also fail to result in academic gains (Elliott et al. 2010). Given such difficulties, and the significant opportunity costs that are often involved, it would seem preferable to use available resources and time to focus upon academic interventions (Jacob and Parkinson 2015; Rabiner et al. 2010) as a means to inform educationalists about the nature and content of educational interventions is greatly weakened. Ultimately, advocates of dynamic assessment would then need to fall back upon its supposed benefits for improved classification and prediction - a direction wholly opposite to that which Elliott (2003) believed was most valuable for teachers, if not educational practice more widely.

There are, of course, many practitioners whose work has been positively influenced by the ideas underpinning dynamic assessment (Green et al. 2005). At the very least, it has sensitised many to the inherent problems of traditional standardised, unassisted testing. However, as Elliott (2003) pointed out, case study reports of educational (school) psychologists testifying to its value (e.g. Lidz and Elliott 2000) are hardly sufficient for the validation of the approach. Rather, what was, and is, needed, was systematic and controlled studies that compare the differential impact of interventions based upon particular dynamic versus static (i.e. traditional) approaches. Of course, here, the focus was upon dynamic assessment, rather than dynamic testing, although this distinction was not carefully drawn at that time.

In seeking to establish validity, however, it is important to understand that (a) dynamic testing/assessment cannot be validated as a general test concept; (b) measures that utilise dynamic approaches need to be validated in their own right; (c) as with any test evaluation, the validation of such measures has to start with a clear definition of the target construct, target population and envisioned purpose of their use; (d) precise definition should lay the foundation for a qualitative - rather than a simplistic quantitative - focus. This examines whether the dynamic test under scrutiny can better predict construct-relevant behaviour (operationalised via an appropriate criterion) than competing traditional approaches, and (e) incremental validity can be achieved via an increase in the sensitivity of a prediction without sacrificing its specificity (Beckmann 2014, 314). Essentially, this means that the test can become more effective in identifying those experiencing a particular difficulty, while at the same time not reduce its capacity to identify those who do not experience such a problem (Beckmann 2006).

In relation to dynamic assessment, Elliott $(2003,24)$ argued that:

... future studies need to examine the extent to which dynamic assessments can: (a) result in recommendations for intervention that are (b) meaningful to, and will be employed by, practitioners (parents, teachers, therapists) and which (c) subsequently demonstrate meaningful gains that are unlikely to have been achieved in their absence. Such studies will be complex and problematic yet may be necessary if the claims of advocates of the approach are to be taken up on a widespread basis. 
Unfortunately, no such studies have been published in the intervening period, and the take up of dynamic approaches by educational psychologists continues to be low (Hill 2015). Sadly, the perceived potential of learning potential (dynamic) assessment continues to remain unfulfilled.

\section{Disclosure statement}

No potential conflict of interest was reported by the authors.

\section{ORCID}

Julian G. Elliott (iD) http://orcid.org/0000-0002-9165-5875

Wilma C. M. Resing (D) http://orcid.org/0000-0003-3864-4517

Jens F. Beckmann (D) http://orcid.org/0000-0002-4006-9999

\section{References}

Aravena, S., J. Tijms, P. Snellings, and M. W. van der Molen. 2016. "Predicting Responsiveness to Intervention in Dyslexia Using Dynamic Assessment." Learning and Individual Differences 49: 209-215.

Banales, E., S. Kohnen, and G. McArthur. 2015. "Can Verbal Working Memory Training Improve Reading?" Cognitive Neuropsychology 32 (3-4): 104-132.

Beckmann, J. F. 2001. Zur Validierung des Konstrukts des Intellektuellen Veränderungspotentials [On the Validation of the Construct of Intellectual Change Potential]. Berlin: Logos.

Beckmann, J. F. 2006. "Superiority: Always and Everywhere? - On Some Misconceptions in the Validation of Dynamic Testing." Educational and Child Psychology 23: 35-49.

Beckmann, J. F. 2014. “The Umbrella That is Too Wide and Yet Too Small: Why Dynamic Testing Has Still Not Delivered on the Promise That Was Never Made." Journal of Cognitive Education and Psychology 13 (3): 308-323.

Borella, E., B. Carretti, and S. Pelgrina. 2010. “The Specific Role of Inhibition in Reading Comprehension in Good and Poor Comprehenders." Journal of Learning Disabilities 43: 541-552.

Büchel, F. P., and U. Scharnhorst. 1993. "The Learning Potential Assessment Device (LPAD): Discussion of Theoretical and Methodological Problems." In Learning Potential Assessment, edited by J. H. M. Hamers, K. Sijtsma and A. J. M. Ruissenaars, 83-111. Amsterdam: Swets and Zeitlinger.

Bull, R., and G. Scerif. 2001. "Executive Functioning as a Predictor of Children's Mathematics Ability: Inhibition, Switching and Working Memory." Developmental Neuropsychology 19 (3): 273-293.

Caffrey, E., D. Fuchs, and L. S. Fuchs. 2008. "The Predictive Validity of Dynamic Assessment: A Review." The Journal of Special Education 41 (4): 254-270.

Cho, E., and D. L. Compton. 2015. "Construct and Incremental Validity of Dynamic Assessment of Decoding Within and Across Domains." Learning and Individual Differences 37: 183-196.

Cho, E., D. L. Compton, D. Fuchs, L. S. Fuchs, and B. Bouton. 2014. "Examining the Predictive Validity of a Dynamic Assessment of Decoding to Forecast Response to Tier 2 Intervention." Journal of Learning Disabilities 47 (5): 409-423.

Cirino, P. T., and E. G. Willcutt. 2017. "An Introduction to the Special Issue: Contributions of Executive Function to Academic Skills." Journal of Learning Disabilities 50 (4): 355-358.

Cirino, P. T., J. Miciak, E. Gerst, M. A. Barnes, S. Vaughn, A. Child, and E. Huston-Warren. 2017. “Executive Function, Self-regulated Learning, and Reading Comprehension: Training Studies." Journal of Learning Disabilities 50: 450-467.

Compton, D. L., D. Fuchs, L. S. Fuchs, B. Bouton, J. K. Gilbert, L. A. Barquero, and R. C. Crouch. 2010. "Selecting At-risk First-grade Readers for Early Interventions: Eliminating False Positives and Exploring the Promise of a Two-stage Gated Screening Process." Journal of Educational Psychology 102: 327-341.

Decker, S. L., J. B. Hale, and D. P. Flanagan. 2013. "Professional Practice Issues in the Assessment of Cognitive Functioning for Educational Applications." Psychology in the School 50: 300-313. 
Diamond, A. 2012. "Activities and Programs that Improve Children's Executive Functions." Current Directions in Psychological Sciences 21: 335-341.

Diamond, A. 2013. "Executive Functions." Annual Review of Psychology 64: 135-168.

Dumas, D. G., and D. M. McNeish. 2017. “Dynamic Measurement Modeling: Using Nonlinear Growth Models to Estimate Student Learning Capacity." Educational Researcher 46 (6): 284-292.

Duncan, G. J., C. J. Dowsett, A. Claessens, K. Magnuson, A. C. Huston, et al. 2007. "School Readiness and Later Achievement." Developmental Psychology 43: 1428-1446.

Dunning, D. L., J. Holmes, and S. E. Gathercole. 2013. "Does Working Memory Training Lead to Generalized Improvements in Children With Low Working Memory? A Randomized Controlled Trial." Developmental Science 16: 915-925.

Elliott, J. G. 2003. “Dynamic Assessment in Educational Settings: Realising Potential.” Educational Review 55: 15-32.

Elliott, J. G., S. E. Gathercole, T. P. Alloway, H. Kirkwood, and J. Holmes. 2010. "An Evaluation of a Classroom-based Intervention to lelp Overcome Working Memory Difficulties." Journal of Cognitive Education and Psychology 9: 227-250.

Elliott, J. G., and W. C. M. Resing. 2015. “Can Intelligence Testing Inform Educational Intervention for Children with Reading Disability?" Journal of Intelligence 3 (4): 137-157.

Estrada, E., E. Ferrer, F. J. Abad, F. J. Román, and R. Colom. 2015. “A General Factor of Intelligence Fails to Account for Changes in Tests'Scores After Cognitive Practice: A Longitudinal Multi-group Latentvariable Study." Intelligence 50: 93-99.

Feuerstein, R., Y. Rand, and M. B. Hoffman. 1979. The Dynamic Assessment of Retarded Performers: The Learning Potential Assessment Device, Theory, Instruments and Techniques. Baltimore, MD: University Park Press.

Feuerstein, R., Y. Rand, M. B. Hoffman, and R. Miller. 1980. Instrumental Enrichment: An Intervention Program for Cognitive Modifiability. Baltimore, MD: University Park Press.

Fisher, R. 2005. Teaching Children to Think. London: Nelson Thornes.

Fletcher, J. M. 2009. "Dyslexia: The Evolution of a Scientific Concept." Journal of the International Neuropsychological Society 15: 501-508.

Fletcher, J. M., G. R. Lyon, L. S. Fuchs, and M. A. Barnes. 2007. Learning Disabilities. New York: Guilford.

Fletcher, J. M., K. K. Stuebing, R. D. Morris, and G. R. Lyon. 2013. “Classification and Definition of Learning Disabilities: A Hybrid Model." In Handbook of learning disabilities. 2nd ed, edited by H. L. Swanson, K. R. Harris and S. Graham, 33-50. New York: Guilford Press.

Fletcher, J. M., and S. Vaughn. 2009. “Response to Intervention: Preventing and Remediating Academic Difficulties." Child Development Perspectives 3: 30-37.

Gellert, A. S., and C. Elbro. 2017.“'Does a Dynamic Test of Phonological Awareness Predict Early Reading Difficulties? A Longitudinal Study From Kindergarten Through Grade 1." Journal of Learning Disabilities 50 (3): 227-237.

Green, T. D., A. S. Mcintosh, V. J. Cook-Morales, and C. Robinson-Zanartu. 2005. “From Old Schools to Tomorrow's Schools: Psychoeducational Assessment of African American students." Remedial and Special Education 26 (2): 82-92.

Gresham, F. M. 2009. “Using Response to Intervention for Identification of Specific Learning Disabilities.” In Behavioral Interventions in Schools: Evidence-based Positive Strategies, edited by A. Akin-Little, S. G. Little, M. A. Bray and T. J. Kehl, 205-220. Washington, DC: American Psychological Association.

Grigorenko, E. L. 2009. "Dynamic Assessment and Response to Intervention: Two Sides of One Coin." Journal of Learning Disabilities 42: 111-132.

Guthke, J. 1982. "The Learning Test Concept - An Alternative to the Traditional Static Intelligence Test." The German Journal of Psychology 6: 306-324.

Guthke, J., and J. F. Beckmann. 2000. “Learning Test Concept and Dynamic Assessment." In Experience of Mediated Learning: An Impact of Feuerstein's Theory in Education and Psychology, edited by A. Kozulin and B. Y. Rand, 175-190. Oxford: Elsevier Science.

Guthke, J., J. F. Beckmann, and K. H. Wiedl. 2003. "Dynamik im Dynamischen Testen." [Dynamics in dynamic testing] Psychologische Rundschau 54: 225-232. 
Guthke, J., and K.-H. Wiedl. 1996. Dynamisches Testen. Zur Psychodiagnostik der Intraindividuellen Variabilität [Dynamic Testing: On the Psycho-diagnostic of Intraindividual Variability]. Göttingen: Hogrefe.

Hale, J. B., C. A. Fiorello, J. A. Miller, K. Wenrich, A. M. Teodori, and J. Henzel. 2008. “WISC-IV Assessment and Intervention Strategies for Children with Specific Learning Difficulties." In WISC-IV Clinical Assessment and Intervention, edited by A. Prifitera, D. H. Saklofske and L. G. Weiss, 109-171. New York: Elsevier.

Hayes, T. R., A. A. Petrov, and P. B. Sederberg. 2015. "Do We Really Become Smarter When Our Fluidintelligence Test Scores Improve?" Intelligence 48: 1-14.

Haywood, H. C. 1993. Interactive Assessment: Assessment of Learning Potential, School Learning, and Adaptive Behavior. Ninth Annual Learning Disorders Conference, Harvard University, Graduate School of Education, Cambridge, MA.

Hessels, M. G. P. 2009. “Estimation of the Predictive Validity of the HART by Means of a Dynamic Test of Geography." Journal of Cognitive Education and Psychology 8 (1): 5-21.

Hill, J. 2015. "How Useful is Dynamic Assessment as an Approach to Service Delivery Within Educational Psychology?" Educational Psychology in Practice 31 (2): 127-136.

Holmes, J., S. E. Gathercole, and D. L. Dunning. 2009. "Adaptive Training Leads to Sustained Enhancement of Poor Working Memory in Children." Developmental Science 12: 9-15.

Jacob, R., and J. Parkinson. 2015. “The Potential for School-based Interventions That Target Executive Function to Improve Academic Achievement: A Review." Review of Educational Research 85: 512-552.

Kearns, D., and D. Fuchs. 2013. "Does Cognitively Focused Instruction Improve the Academic Performance of Low-achieving Students?" Exceptional Children 79 (3): 263-290.

Kern, B. 1930. Wirkungsformen der Übung [Effect Patterns of Practice]. Münster: Helios.

King, M. R., C. Binger, and J. Kent-Walsh. 2015. "Using Dynamic Assessment to Evaluate the Expressive Syntax of Children who Use Augmentative and Alternative Communication." Augmentative and Alternative Communication 31 (1): 1-14.

Kirk, H. E., K. Gray, D. M. Riby, and K. M. Cornish. 2015. "Cognitive Training as a Resolution for Early Executive Function Difficulties in Children with Intellectual Disabilities." Research in Developmental Disabilities 38: 145-160.

Lidz, C., and J. Elliott, eds. 2000. Dynamic Assessment: Prevailing Models and Applications. New York: J.A.I. Press.

McGuinness, C. 1999. From Thinking Skills to Thinking Classrooms: A Review and Evaluation of Approaches for Developing Pupils' Thinking. Research Report 115. London: HMSO.

McNeil, L. 2016. "Understanding and Addressing the Challenges of Learning Computer-mediated Dynamic Assessment: A Teacher Education Study." Language Teaching Research. Advance online publication. doi:10.1177/1362168816668675

McNeish, D., and D. Dumas. 2017. "Non-linear Growth Models as Measurement Models: A Secondorder Growth Curve Model for Measuring Potential." Multivariate Behavioral Research 52 (1): 61-85.

Melby-Lervåg, M., and C. Hulme. 2013. "Is Working Memory Training Effective? A Meta-analytic Review." Developmental Psychology 49: 270-291.

Nayfield, I., J. Fuccillo, and D. B. Greenfield. 2013. "Executive Functions in Early Learning: Extending the Relationship Between Executive Functions and School Readiness to Science." Learning and Individual Differences 26: 81-88.

Passig, D., D. Tzuriel, and G. Eshel-Kedmi. 2016. “Improving Children's Cognitive Modifiability by Dynamic Assessment in 3D Immersive Virtual Reality Environments." Computers and Education 95: 296-308.

Peltenburg, M., M. van den Heuvel-Panhuizen, and B. Doig. 2009."Mathematical Power of Special-needs Pupils: An ICT-based Dynamic Assessment Format to Reveal Weak Pupils' Learning Potential." British Journal of Educational Technology 40 (2): 273-284.

Petersen, D. B., and R. B. Gillam. 2015. “Predicting Reading Ability for Bilingual Latino Children Using Dynamic Assessment." Journal of Learning Disabilities 48 (1): 3-21.

Poehner, M. E., J. Zhang, and X. Lu. 2015. “Computerized Dynamic Assessment (CDA): Diagnosing L2 Development According to Learner Responsiveness to Mediation." Language Testing 32: 337-357.

Rabiner, D. L., D. W. Murray, A. T. Skinner, and P. S. Malone. 2010. "A Randomized Trial of Two Promising Computer-based Interventions for Students with Attention Difficulties." Journal of Abnormal Child Psychology 38: 131-142. 
Redick, T. S. 2015. "Working Memory Training and Interpreting Interactions in Intelligence Interventions." Intelligence 50: 14-20.

Redick, T. S., Z. Shipstead, E. A. Wiemmers, M. Melby-Lervåg, and C. Hulme. 2015. "What's Working in Working Memory Training? An Educational Perspective." Educational Psychology Review 27 (4): 617-633.

Reschly, D. J., and W. D. Tilley. 1999. "Reform Trends and System Design Alternatives." In Special Education in Transition: Functional Assessment and Noncategorical Programming, edited by D. J. Reschly, W. D. Tilley and J. P. Grimes, 19-48. Longmont, CO: Sopris West.

Resing, W. C. M., M. Bakker, C. M. Pronk, and J. G. Elliott. 2016. "Dynamic Testing and Transfer: An Examination of Children's Problem-solving Strategies." Learning and Individual Differences. 49: 110119.

Resing, W. C. M., M. Bakker, C. M. Pronk, and J. G. Elliott. 2017.“Progression Paths in Children's Problem Solving: The Influence of Dynamic Testing, Initial Variability and Working-memory." Journal of Experimental Child Psychology 153: 83-109.

Resing, W. C., and J. G. Elliott. 2011. “Dynamic Testing with Tangible Electronics: Measuring Children's Change in Strategy Use with a Series Completion Task." British Journal of Educational Psychology 81: 579-605.

Resing, W. C., K. W. Touw, J. Veerbeek, and J. G. Elliott. 2017. "Progress in the Inductive Strategy-use of Children from Different Ethnic Backgrounds: A Study Employing Dynamic Testing." Educational Psychology 37 (2): 173-191.

Resing, W. C. M., E. Tunteler, and J. G. Elliott. 2015. "The Effect of Dynamic Testing With Electronic Prompts and Scaffolds on Children's Inductive Reasoning: A Microgenetic Study." Journal of Cognitive Education and Psychology 14 (2): 231-251.

Resing, W. C., I. Xenidou-Dervou, W. M. P. Steijn, and J. G. Elliott. 2012. “A 'Picture' of Children's Potential for Learning: Looking into Strategy Changes and Working Memory by Dynamic Testing." Learning and Individual Differences 22: 144-150.

Reynolds, C. R., and S. E. Shaywitz. 2009. "Response to Intervention: Prevention and Remediation, Perhaps. Diagnosis, No." Child Development Perspectives 3: 44-47.

Sasser, T. R., K. L. Bierman, and B. Heinrichs. 2015. “Executive Functioning and School Adjustment:The Mediational Role of Pre-kindergarten Learning-related Behaviors." Early Childhood Research Quarterly 30: 70-79.

Seethaler, P. M., L. S. Fuchs, D. Fuchs, and D. L. Compton. 2016. “Does the Value of Dynamic Assessment in Predicting End-of-first-grade Mathematics Performance Differ as a Function of English Language Proficiency?" The Elementary School Journal 117 (2): 171-191.

Simons, D. J., W. R. Boot, N. Charness, S. E. Gathercole, C. F. Chabris, D. Z. Hambrick, and E. A. StineMorrow. 2016. "Do 'Brain-Training' Programs Work?" Psychological Science in the Public Interest 17 (3): 103-186.

Sternberg, R. J., and E. L. Grigorenko. 2002. Dynamic Testing: The Nature and Measurement of Learning Potential. Cambridge: Cambridge University Press.

Stevenson, C. E., W. J. Heiser, and W. C. Resing. 2016. “Dynamic Testing: Assessing Cognitive Potential of Children with Culturally Diverse Backgrounds." Learning and Individual Differences 47: 27-36.

Tzuriel, D. 2013. "Mediated Learning Experience and Cognitive Modifiability." Journal of Cognitive Education and Psychology 12 (1): 59-80.

Veerbeek, J., J. Verhaegh, J. G. Elliott, and W. C. Resing. 2017. “Process-oriented Measurement Using Electronic Tangibles." Journal of Education and Learning 6 (2): 155.

Wass, S. V. 2015. "Applying Cognitive Training to Target Executive Functions During Early Development." Child Neuropsychology 21 (2): 150-166.

Zhang, R. C., H. M. Lai, P. W. Cheng, and C. P. Chen. 2017. “Longitudinal Effect of a Computer-based Graduated Prompting Assessment on Students' Academic Performance." Computers and Education 110: 181-194. 